\title{
A NEW METHODOLOGY FOR ACCIDENTS ANALYSIS: THE CASE OF THE STATE ROAD 36 IN ITALY
}

\author{
FABIO BORGHETTI ${ }^{1}$, GIOVANNA MARCHIONNI ${ }^{1}$, MATTEO DE BIANCHI ${ }^{1}$, BENEDETTO BARABINO $^{2}$, \\ MICHELA BONERA ${ }^{2} \&$ CLAUDIA CABALLINI ${ }^{3}$ \\ ${ }^{1}$ Mobility and Transport Laboratory - Design Department - Politecnico di Milano, Italy \\ ${ }^{2}$ Department of Civil Engineering, Architecture, Land, Environment and Mathematics (DICATAM) - University of \\ Brescia, Italy \\ ${ }^{3}$ Department of Environment, Land and Infrastructure Engineering (DIATI) - Politecnico di Torino, Italy
}

\begin{abstract}
Every year more than 1.35 million people die for road accidents and several million suffer serious injuries, which force them to live with compromised health conditions. Over the last decades, road safety research has focused on improving modelling techniques. However, due to the lack of expertise and statistical skills, such approaches might not be used by local authorities and road managers for road safety evaluation purposes. This paper proposes an operational methodology to analyze road accidents with the aim of increasing road safety. More specifically, the methodology enables to identify the most critical road segments to prioritize economic resources allocation accordingly. By using the data collected by the Road Police Department of Lombardy Region (in Italy) from 2014 to 2018, this methodology has been successfully applied to State Road 36, which is recognized as one of the busiest roads in Italy with a very high number of accidents occurring every year. The proposed methodology may support public administrations and road managers - involved in the definition and implementation of safety measures - to reduce the number of road accidents identifying and implementing prioritized interventions. Moreover, the methodology is general enough to be applied to each segment of a generic road infrastructure.

Keywords: decision support system, GIS, road accident analysis, road safety analysis, road safety framework, road transportation infrastructure, statistical data.
\end{abstract}

\section{INTRODUCTION}

Every year more than 1.35 million people die on the roads and some millions suffers serious injuries. Also, road accidents are the leading cause of fatalities for people aged 15-29, worldwide. The objective of halving the number of road deaths and serious injuries has been renewed towards the 2050 'Vision Zero' [1,2].

From a technical-scientific viewpoint, road accidents analysis aimed at increasing road safety can be performed by using two main approaches: a 'model-centered' approach, in which mathematical models are adopted to estimate frequencies and severity and to define and apply preventive measures, and a 'data-centered' approach aiming at defining better safety measures by analyzing historical road accident data.

As for the 'model-centered' approach, researchers usually propose and apply accurate and sophisticated quantitative models and methods, specifically aimed at analyzing road safety risks, predicting accident frequency and severity and measuring the impact that risk factors have on accident occurrences ([3]; [4]). The American Highway Safety Manual (HSM) is one of the main references worldwide for what concerns accident prediction models [5]. Owing to their predictive capabilities, such methods have been largely applied in several studies 
to test the transferability of the HSM approach to conditions other than the American ones, both for rural and urban networks (e.g., [6]; [7]; [8]). Although such calibration resulted to be fairly satisfying (for rural rather than urban road), site-specific models are largely recommended, as they enable more accurate predictions for the specific contexts (e.g., [9]; [10]). The 'model-centered' approach is not often of immediate use, especially considering that decision-making subjects (i.e., public administrations, road managers, etc.) do not have sufficient technical skills and competences to apply them and interpret their results.

As for the 'data-centered' approach, it is crucial to record and collect accurate data from different sources, verify and integrate them according to specific needs. This approach can be applied when a representative time horizon is available. On the one hand, complex analytical models are generally not required, thus data processing can be done quickly and easily. On the other hand, it is necessary to stress the importance of recording and collecting data properly and continuously for the analysis and evaluation of the safety of different types of road infrastructures (i.e., open air sections, tunnels, etc.) [11]. The importance of data collection process is also highlighted by Imprialou and Quddus [12], who critically analyzed data shortcomings due to accident-reporting issues, data incompleteness and accuracy, referring to the principle of 'Garbage in garbage out', and by Schlögl and Stütz [13], who classified accident information into three main categories (accident location, vehicle and person-related information).

Focusing on the 'data-centered' approach, this paper proposes an operational straightforward methodology for the evaluation of the road infrastructures safety performances and the definition of road safety measures to increase road safety. Moreover, the overall methodology relies on road accident official statistics data, which are standardized and generally publicly available, to make the whole process widely replicable. The user-friendliness of the method enables to easily identify the most critical road segments so that resources can be allocated more efficiently and in a prioritized way. In doing so, the proposed method represents an effective decision support system capable of helping both public and private stakeholders such as road managers and Administrators - in dealing with road safety.

The remaining of the paper is structured as follows. In Section 2 the proposed methodology is explained, whereas in Section 3 the application of the approach to a real case study is provided. Finally, some conclusions are outlined in Section 4.

\section{METHODOLOGY}

The proposed methodology is composed of five steps, which are reported in Fig. 1. Specifically, by using simple and well-known indicators, this methodology aims at making the road safety evaluation process easier, using a step-by-step selection of the 'worst-performing' road segments depending on the road safety indicators considered in each step. In doing so, the methodology helps save time and resources: less detailed data are required in the first steps, where the whole road infrastructure is concerned, and only in the last steps more detailed data are used to produce in-depth analysis, which are however confined to a limited set of segments. Each step is briefly described in what follows.

Step 1. The first step concerns the collection of road accident data from official statistical sources. Relying on the official data enables an easy replicability and adaptability of the overall methodology, being this data standardized at the national level. Such data usually contains the road accident location and type, the number of people involved and their consequences, road, and site characteristics, etc. A study period of at least 3-5 years must be set as reference for the data collection, to ensure a sufficient time horizon for the analysis. 


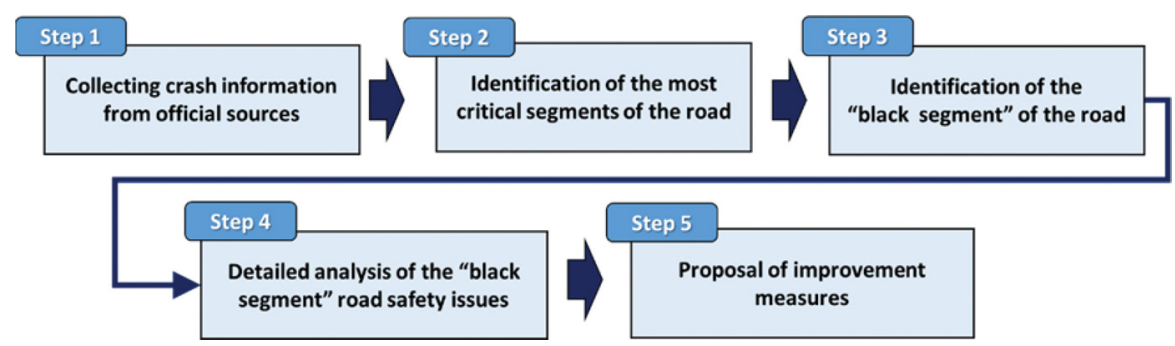

Figure 1: 5-steps methodological framework.

Step 2. This step aims at identifying the segments with the highest road accident frequency. First, the whole road is divided into fixed-length segments (e.g., $1 \mathrm{~km}$ each) and, for each segment, the road accident frequency is computed over the considered study period, according to this formula:

$$
\text { Road accident frequency }=\frac{\text { Number of accidents }}{\text { Study period }[\text { years }]}
$$

Then, just the first $k$ segments with the highest accident frequency based on a defined threshold are input in the following steps.

Step 3. This step aims at identifying the 'black segment', i.e., the one showing the worst safety performances among the $k$ segments with the highest road accident frequency. To evaluate road safety performances, a set of Key Performance Indicators (KPIs) should be selected. Among the many KPIs available in the literature, just a few and representative ones have been selected in this paper, to make the evaluation process easier and faster. Specifically, the rationale is that such KPIs must be considered in an ordered logic, to enable a cascading comparison between them to return the 'black segment'. Starting from the first KPI, for each of the $k$ segments the related values are computed and then compared to identify the highest one. If several segments return the same KPI value or data are not sufficient to compute it, the next KPI is considered, and the same procedure is run. The KPIs considered are the following:

$$
\begin{aligned}
\text { Road Accident Rate } & =\frac{\text { Number of accidents }}{10^{8} \text { vehicles*km }} \\
\text { Social Cost Index } & =\frac{\text { social costs }[€]}{\text { study period }[\text { years }]} \\
\text { Mortality Index } & =\frac{\text { Number of fatalities }}{100 \text { accidents }} \\
\text { Severity Index } & =\frac{\text { Number of fatalities }}{\text { Number of injuries }}
\end{aligned}
$$




$$
\text { Injury Index }=\frac{\text { Number of injuries }}{100 \text { accidents }}
$$

Road accident rate is evaluated first as it returns an assessment of the road accident occurrence against an exposure measure (i.e., the traffic flow) [14]. Social Cost Index are appointed as second, being an estimate of the economic damage suffered by the community as a result of road accidents [15]. It can be simply computed by multiplying the number of deaths, injuries and accidents by the related average cost. Then, also the mortality, severity and injury indices are listed, to account for the severity of road accidents.

Step 4. Once the 'black segment' has been identified, this step provides a focused evaluation of the road infrastructure and operational characteristic of such segment. In this step, more detailed data (e.g., weather conditions, visibility, pavement state, heading, vehicle features, etc.) are considered, which are necessary to identify specific issues which can either lead to road accidents or affect road accident consequences. If necessary, on-field inspections should be also considered to collect further site-related information. Specifically, the following aspects must be considered:

- Road accident location: actual road accident position (e.g., localization, travel direction, etc.) and site type (e.g., curve, junction, tunnel, longitudinal and transverse slope, etc.).

- Road segment design characteristics: cross section features (e.g., number of carriageways and lane, etc.), road signs (e.g., overtaking lane, etc.) and road surface condition (e.g., type of pavement, surface maintenance, etc.).

- Driver behaviour and violations: user behaviours that cause road safety issues, road accident dynamics, etc.

- Type of vehicles involved: proportion of heavy vehicle (HV) and light vehicles (LV) related to total traffic volumes, or specific vehicle types.

- Time-fluctuation of road accident: distribution of the number of accidents over the year, weekdays and time of the day.

- Effect of traffic and weather condition: crash occurrence with respect to weather conditions and traffic flows.

Step 5. The last step concerns the proposal of specific corrective measures that aim at improving the road safety performance of the 'black segment'. The choice of the interventions is strictly related to the problems emerged in the previous step, and may include both infrastructural (e.g., rebuild of the road pavement, introduction of new road signs, etc.) and road management actions (e.g., change of speed limits, the introduction of overtaking prohibitions, restriction to some types of vehicles, etc.).

\section{CASE STUDY: STATE ROAD 36 IN ITALY}

\subsection{Case study and data description}

By using the data collected by the Road Police Department of Lombardy Region (in Italy) over the period 2014-2018, the proposed methodology has been applied to the State Road 36 (SS36) in Italy, which is considered as one of the busiest roads in Italy with a very number of accidents [16]. This road segment is located in Northern Italy in Lombardy Region, connecting the suburbs of the city of Milan with Switzerland (Spluga Pass), and is managed by 


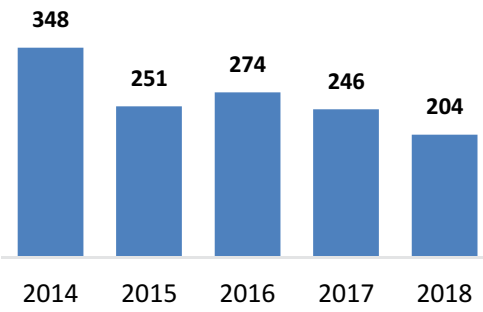

Figure 2: Distribution of the number of accidents by year during 2014-2018 (Source: Road Police Department of Lombardy Region).

ANAS S.p.A. The route is about $141 \mathrm{~km}$ long and represents the main access route to Valtellina and Engadine Valleys in the Swiss canton of Grigioni. The infrastructure consists of two divided carriageways, with 2-3 lanes in each direction; in addition, in the northernmost part there are several segments passing under viaducts and tunnels. The Average Daily Traffic (ADT) ranges from 19,723 to 73,095 vehicle per day.

According to step 1, the data required to run the methodology were provided by the Road Police of Lecco which has competence on the stretch of the road under study in matter of road accident recording. In fact, in the event of an accident, the Road Police intervenes and carries out surveys by completing standard forms, which are subsequently cataloged and archived according to the national official statistics road accident template. In this work, the first 100 $\mathrm{km}$ of State Road 36 were analyzed. Figure 2 shows the number of road accident occurred over this road stretch over the 5-year period considered (2014-2018). Although a reduction in road accident was registered over the 5-year period, still a high number (more than 200) of accident occur over this segment.

\subsection{Results and discussion}

The data acquired in the previous step have been checked and analyzed by spreadsheets. Moreover, using a Geographic Information System (GIS) software, it was possible to map the recorded road accidents so that each segment could be related to the relative road accidents. According to step 2, the track of the SS36 was divided in 1-km length segments and, for each one, the road accident frequency was computed according to eqn (1). The five segments with the highest road accident frequency were identified, according to a road accident frequency threshold of 50 road accident $/ 5$ years.

Figure 3 shows a colored-scale representation of the five most critical segments. Figure 4 reports the road accident frequencies for all the segments analyzed, and the five most critical ones are highlighted in red. According to step 3, after identifying the five critical kilometers, it was possible to proceed by compute the KPIs for the identification of the 'black segment', according to eqns. (2)-(6). Table 1 summarizes the calculations of the KPIs for the five segments in the period 2014-2018. Moreover, they are reported according to the ordered

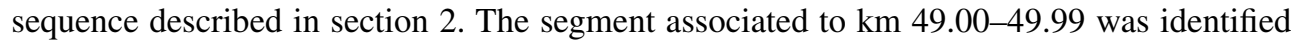
as the 'black kilometer'.

Indeed, according to the methodology rationale, this segment reported the highest value of the road accident rate (i.e., 74.96 events $/ 10^{8}$ vehicles $\mathrm{km}$ ), which is the first KPI to be considered in the proposed procedure. Given that no other segment showed a similar value of the road accident rate, the KPIs cascading comparison ended. 


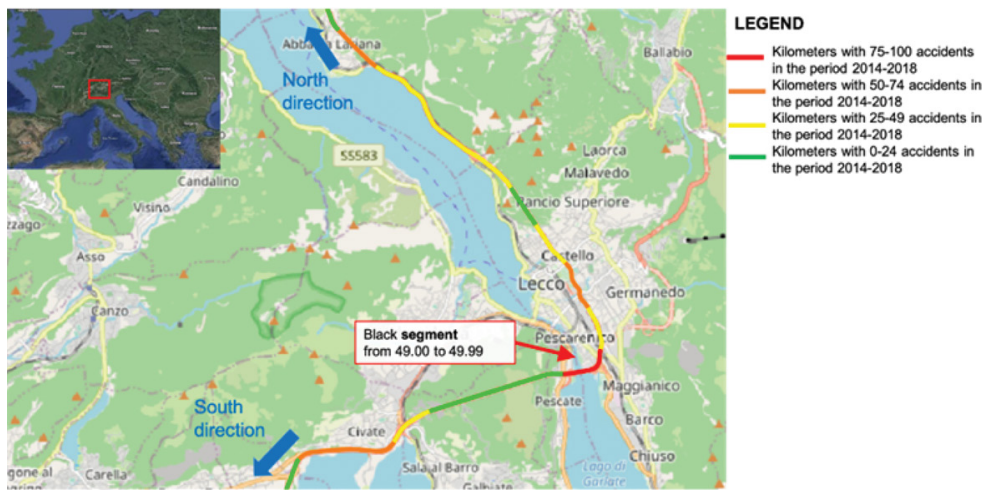

Figure 3: Coloured-scale representation of the critical segments (zoom of the scratch of the State Road 36 where they are localized). Source: www.openstreetmap.org.
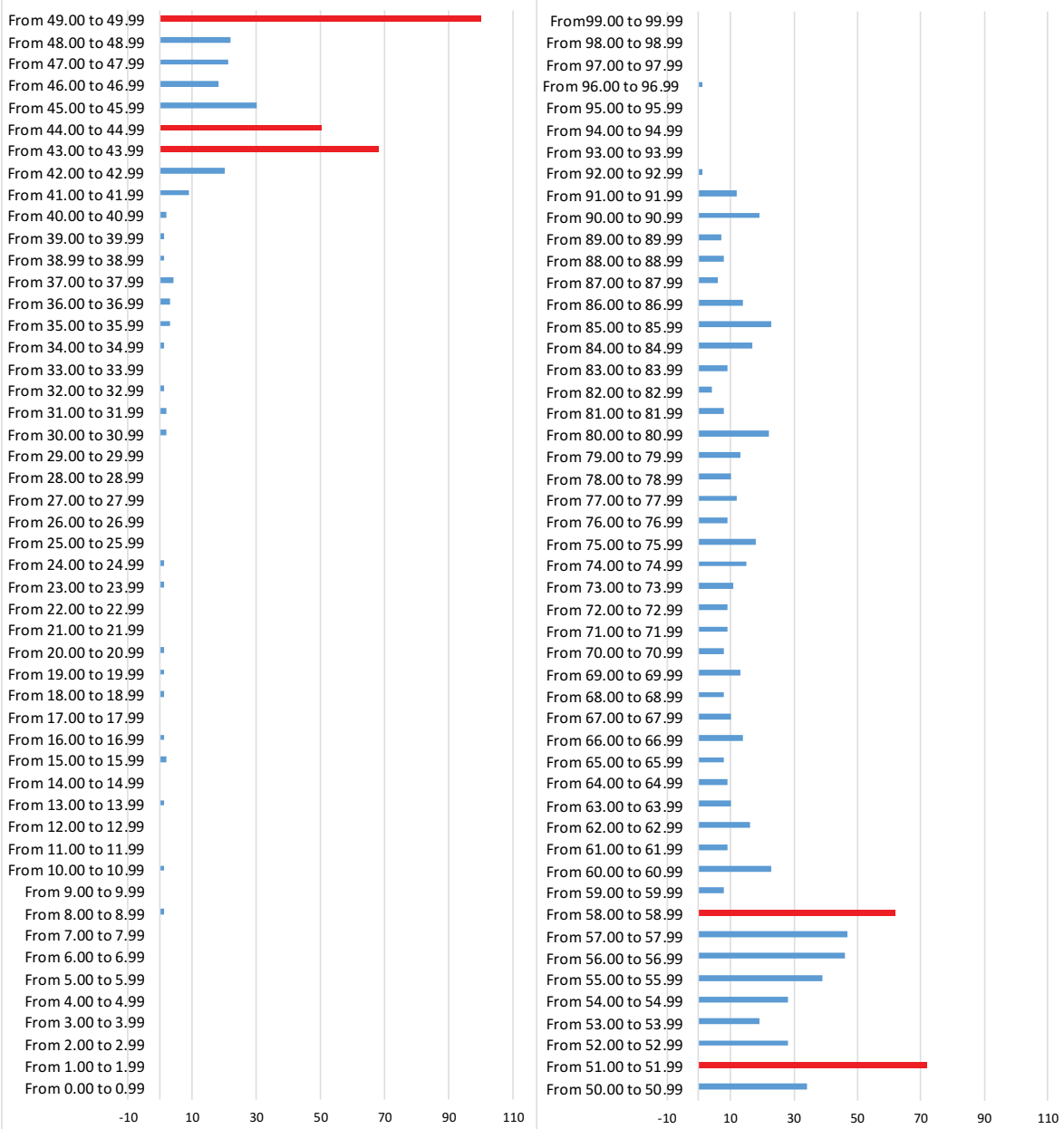

Figure 4: Road accident frequency for the 100 segments of the SS36 over the period 20142018 (Source: Road Police Department of Lombardy Region). 


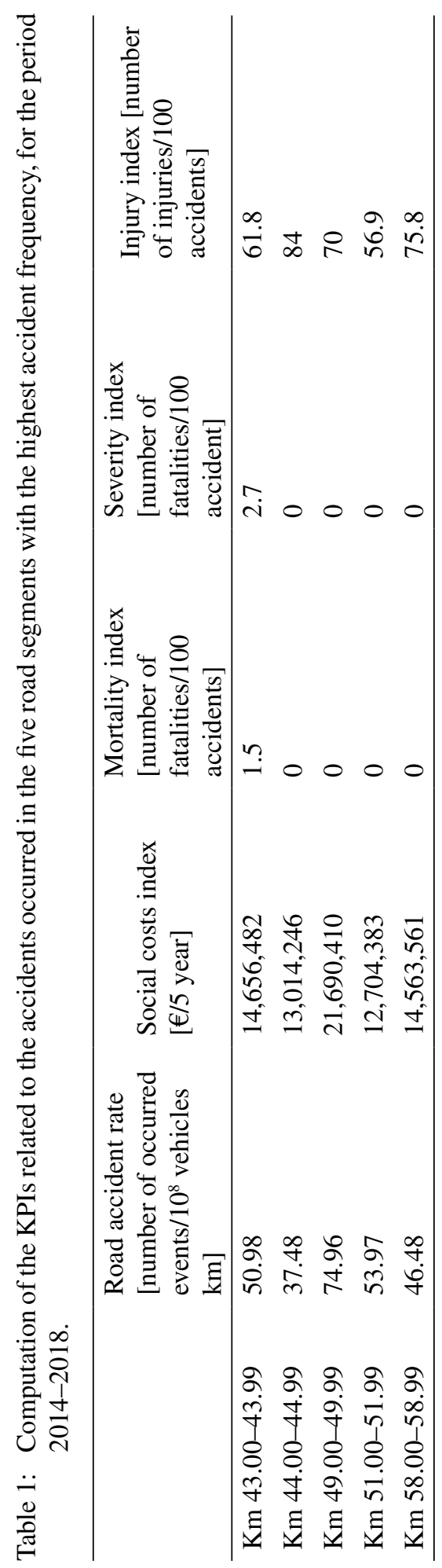


In case the Social Costs Index should had been considered in cascade, it would have confirmed the previous result, since the $\mathrm{km} \mathrm{49.00-49.99}$ is associated with the highest social cost value (i.e., 21,690,410 €/5 years). Specifically, the Social Cost index was computed according to the study conducted by the Italian Ministry of Infrastructure and Transport in 2017 [17], which returns the average human cost per each death, per each injured person, and the average general costs for a road accident. Specifically, they are assumed to be equal to $1,503,990 €, 42,219 €$ and $10,986 €$, respectively. As for the Mortality and Severity Indices, the only non-null value was associated to $\mathrm{km} 43.00-43.99$ since some deaths were registered in that segment over the considered 5-year period. However, according the methodology rationale, the road accident rate and the social costs index associated to km 43.00-43.99 are ranged third for road accident rate and second for the Social Cost Index, respectively. Hence, according to the cascading comparison they would have not been considered.

Once the 'black segment' was detected, further data were analyzed according to step 4, and additional information were considered to obtain a more complete picture of the safety performance of such segment, so that the risk factors could be identified. Based on the bullet points provided in step 4 (methodology section), detailed analyses were performed, and the main results are reported in the following.

As for road accident location, Fig. 5 shows the actual position of each road accident over the 'black segment' by mean of the GIS software, while Fig. 6 shows the distribution of the road accidents by site types and travelling directions. As for site type, the sections with the highest road accident frequency are the straight (49) and turn (45) sections. Also, the concentration of road accidents in correspondence to merging ramps (either entrance and

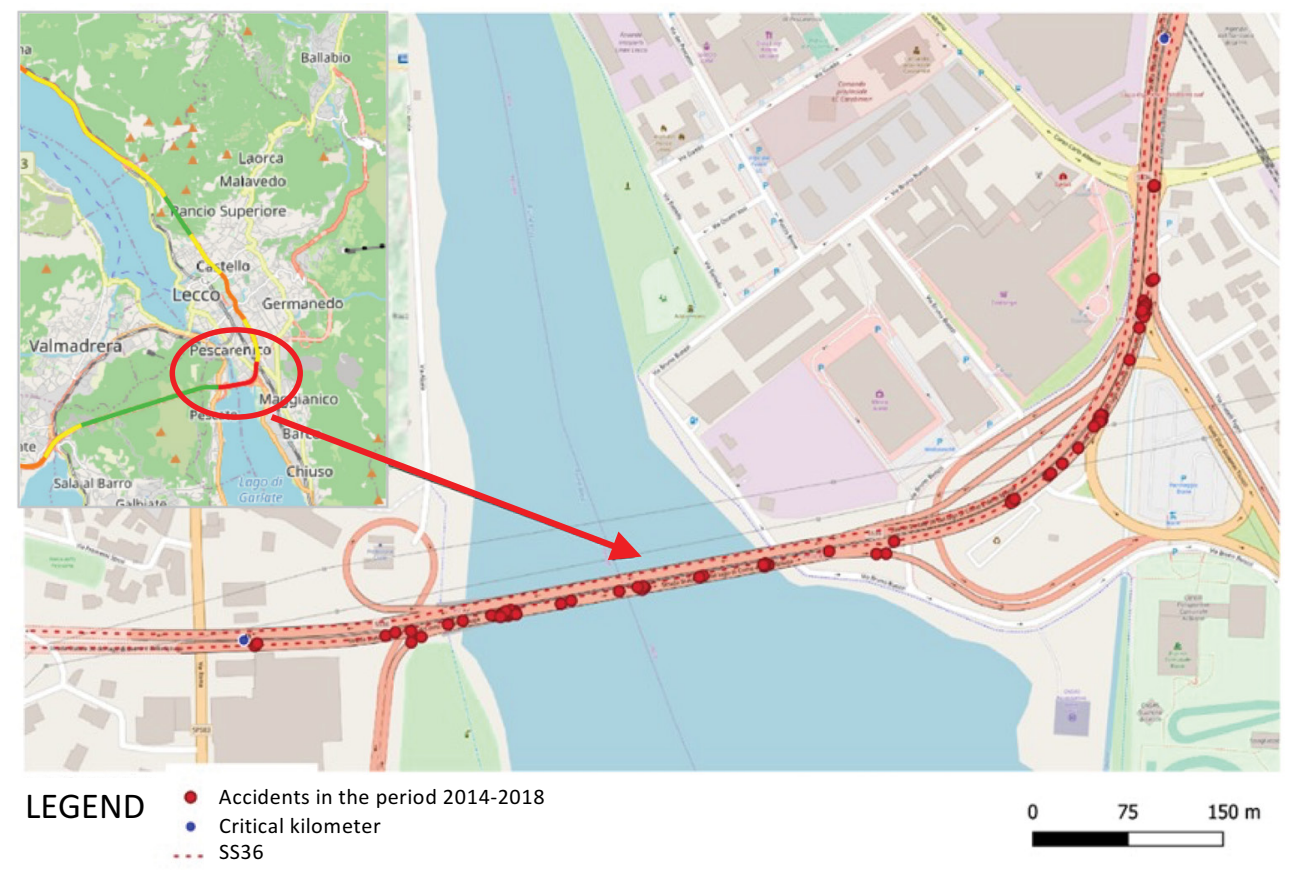

Figure 5: Location of accidents over the black segment in the South-North direction of the black segment. Source: www.openstreetmap.org. 
exit ramps) was registered; these accidents are due to the interference between passing and merging traffic. As for travel direction, 67 road accidents occurred in South-North direction; in this direction vehicles come from the Monte Barro tunnel, which may generate difficulty for users to adjust their sight to the light change, or distraction due to the change of the road environment (from closed to open).

As for road segment design characteristics, due to the lack of specific data from the road police records, some on-field inspections have been carried out to collect further site-related information. Specifically, some of the road signs related to the merging ramps/lanes were not fully visible and not completely perceived (Fig. 7). Also, road surface conditions were investigated and found to be poorly maintained in some sections.

Considering drivers' behavior and violations, the possible causes of road accidents were analyzed, as illustrated in Fig. 8. It emerges that the most common cause is represented by the high speed of vehicles (38). Actually, speed limits have been reduced several times (currently the limit is $70 \mathrm{~km} / \mathrm{h}$ for a first stretch and then increase at $90 \mathrm{~km} / \mathrm{h}$ in the straight portion distant from the ramps), but in many cases they are not respected by drivers.

As for the type of vehicles involved, Table 2 shows the average daily traffic and the percentages of heavy vehicles (HV) and light vehicles (LV) in some traffic detection stations along the State Road 36, for the year 2018; note that LV includes also motorcycles and other powered two wheelers (PTW). From the road accident data collected, it emerged that many motorcycles were involved (and specifically 87.5 injuries/100 accident).

Accident location on critical kilometer (2014 - 2018) $3 \quad 3$

- Exit ramp

- Turn

- Straight

- Entrance ramp

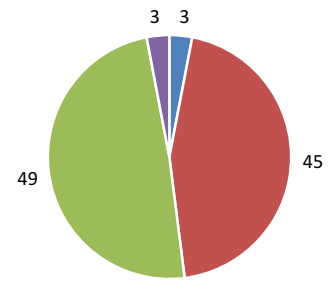

Direction of vehicles involved in accidents on critical kilometer (2014 - 2018)

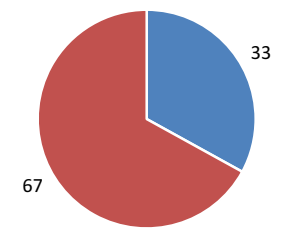

Figure 6: Distribution of the road accidents by site type (left side) and travelling direction (right side) for the black segment.

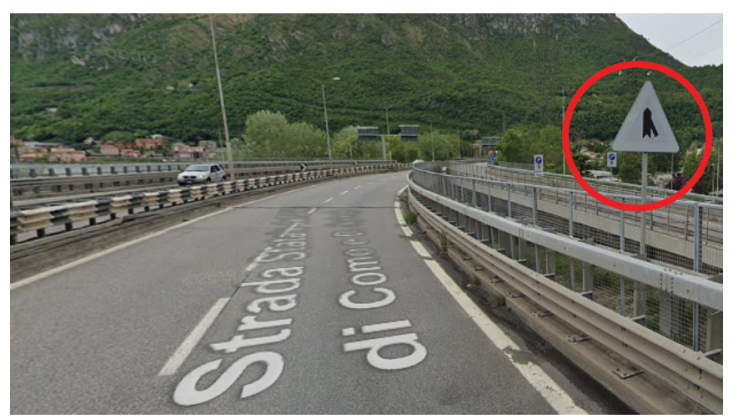

Figure 7: Example of not fully visible vertical road sign, close to the merging ramp. Source: www.google.it/map. 


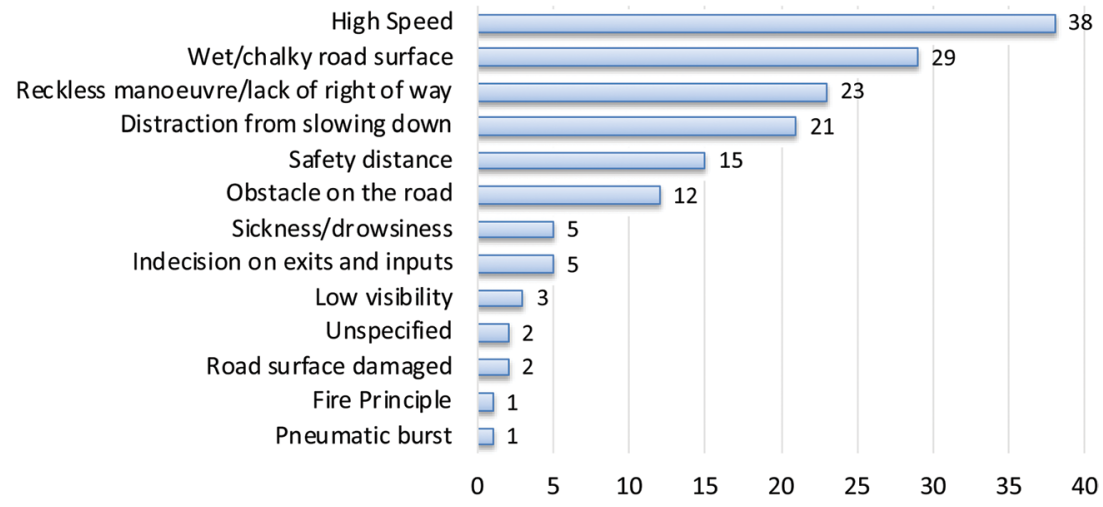

Figure 8: Causes of road accidents in relation to the black segment in the period 2014-2018.

Table 2: Average daily traffic and percentages of HV and LV in the traffic detection stations, for the year 2018 .

\begin{tabular}{llllll}
\hline Traffic detection station & Light vehicles & Heavy vehicles & TOT & $\%$ LV & $\% \mathrm{HV}$ \\
\hline Km 34 & 50,759 & 3,262 & 54,021 & $94 \%$ & $6 \%$ \\
Km 23 & 88,987 & 4,758 & 93,745 & $95 \%$ & $5 \%$ \\
Km 59 & 19,048 & 1,752 & 20,800 & $92 \%$ & $8 \%$ \\
& & & Average value & $93 \%$ & $7 \%$ \\
\hline
\end{tabular}

As for road accidents time-fluctuation, the distribution of accidents at the weekly and hourly levels were evaluated, as shown in Fig. 8. Overall, there is no difference between weekend and weekday accidents. In the afternoon, from 2:00 p.m. to 7:00 p.m., the greatest number of accidents is observed. Instead, almost one-third of the accidents occur in the morning band.

As for the effects of traffic and weather condition, Fig. 10 shows that most of the accidents occurred during intense (42) and regular (46) traffic conditions. As for the weather conditions, the largest number of road accidents occurred in favorable weather conditions (58), while about one over three road accidents occurred in rainy conditions (32); since the majority of the days of the considered time period were rainy, we can state that rain affects the number of road accidents.

According to step 5, based on such detailed analysis, some interventions have been proposed to improve the road safety performances of the km 49.00-49.99: (i) introduction of new and more visible road signs (horizontal and vertical); (ii) improvement of road readability, specifically at curves; and (iii) definition of a maintenance program of the road surface. As for (i), the aim is to increase the attention of users in the points where the analyses have highlighted a significant number of road accidents, such as the merging ramp areas. Moreover, as a high number of PTW were involved in road accidents, specific overtaking limitation road signs should be installed to alert users. It is believed that, thanks to the introduction of new road signs (e.g., backlit road signs), many types of collisions (rear-end, collisions due to lane changes near a ramp and collisions during the main entry) should significantly decrease. 


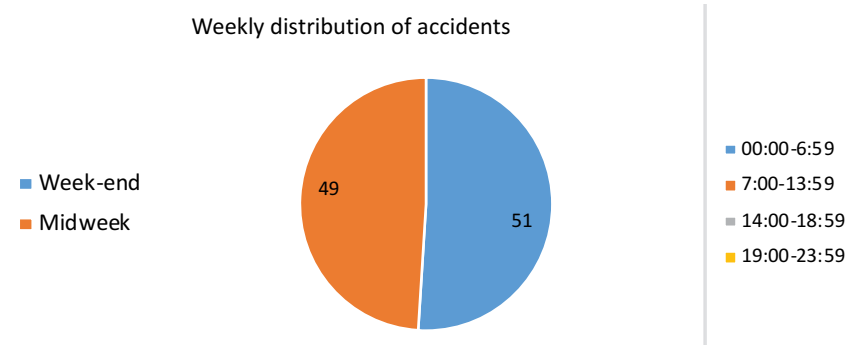

\section{Time distribution of accidents}

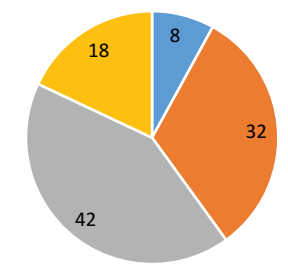

Figure 9: Weekly (left side) and time (right side) distribution of accidents relating to the black segment.
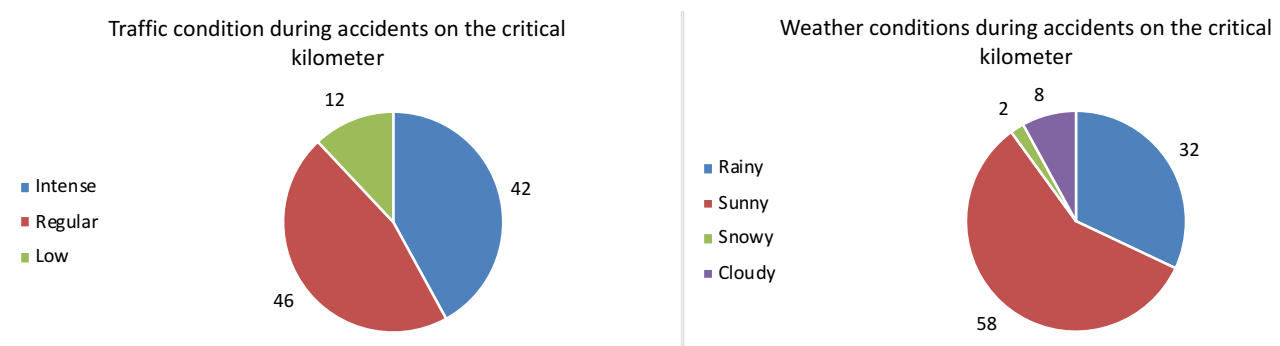

Figure 10: Traffic (left side) and weather (right side) conditions relating to the black segment.

The quantification of this reduction is left to subsequent monitoring studies of the critical segment. As for (ii), it is proposed to use modular curve delimiters coupled with a sequential luminous system: this solution enable to improve drivers' perception and to reduce in advance the vehicle speed while entering a curve. Moreover, such element can help in limiting the average speed of passing vehicles. Finally, regarding (iii), as the decay of the porous properties of the pavement increases over time, the surface permeability decreases as well as slip resistance and, ultimately, this leads to an increase in road accidents [18]. As for the case study, cleaning the flooring twice a year and, precisely, in the months of June and December, is a recommended action. From an operational viewpoint, a solution is proposed in which the surface is sprayed with water at high pressure and the water mixed with dirt is removed from the pores by suction [19].

\section{CONCLUSIONS}

This paper proposes an operating and straightforward methodology to perform road safety analysis. By using simple KPIs, it enables to sort road segments step-by-step to identify the most critical one, defined as the 'black segment'. In doing so, the approach enables to save time and resources to perform road safety analysis, which is crucial for local road Authorities. The type of road accident data to be collected and how to use them are indicated by the proposed methodology, which also provides a set of KPIs with their relative priority to identify the most critical road segments correctly and efficiently. The methodology was successfully tested on the State Road 36 located in Northern Italy. Easy-to-read control dashboards showed the viability of this methodology. In addition, this methodology can act as a decision support system for the evaluation and management of road safety. First, it can support 
administrations and public bodies to elaborate statistics and analyze the safety status of road infrastructures to better allocate resources accordingly. Second, it can help road infrastructure managers to prioritize road safety measures with the goal of drastically reducing the number of road accidents. If, on the one hand, the proposed methodology is easy to apply, on the other hand, it shows some limitations and constraints. First, it requires disaggregated data, and specifically all road accident must be geo-localized along the road; moreover, it is very important to have data recorded and validated by official institutions. To correctly apply the proposed methodology, all data must be listed, otherwise the KPIs cascading comparison cannot be applied. Another constraint concerns the format of data and information that must be collected and recorded following an accident: it is necessary to define a guideline for the acquisition of data in order to support the personnel in charge (e.g., road police). A further aspect concerns the comparative approach of the proposed method: it is necessary to divide the road infrastructure into sections of homogeneous length (e.g., $1 \mathrm{~km}$ ), otherwise it is not possible to make a comparison using the different KPIs.

Further research will be devoted to understanding how the several KPIs here proposed can be combined to return a composite index to evaluate road safety performance in a single step.

\section{REFERENCES}

[1] WHO World Health Organization. Global Status Report on Road Safety 2018: Summary. World Health Organization, 2018.

[2] European Union. EU road safety policy framework 2021-2030. Next steps towards 'Vision Zero'. Commission Staff Working Document SWD (2019) 283 final, 2020.

[3] Lord, D. \& Mannering, F.L., The statistical analysis of accident-frequency data: a review and assessment of methodological alternatives. Transportation research part A: policy and practice, 44(5), pp. 291-305, 2010.

[4] Mannering, F.L. \& Bhat, C.R., Analytic methods in road accident research: methodological frontier and future directions. Analytic Methods in Road Accident Research, 1, pp. 1-22, 2014.

[5] American Association of State Highway and Transportation Officials (AASHTO). Highway safety manual. Washington, DC, USA, 2010.

[6] Bonera, M. \& Maternini, G., Methodology for the application of predictive method for road safety analysis in urban areas. the case study of Brescia. Transportation Research Procedia, 45, pp. 659-667, 2020.

[7] Farid, A., Abdel-Aty , M., Lee, J., Eluru \& N., Wang, J., 2016. Exploring the transferability of safety performance functions. Accident Analysis and Prevention, 94, pp. 143-152, 2016.

[8] La Torre, F., Domenichini, L., Meocci, M., Graham, D., Karathodorou, N., Richter, T., Ruhlc S., Yannis G., Dragomantovits A. \& Laiou, A., Development of a transnational road accident prediction model. Transportation Research Procedia, 14, pp. 1772-1781, 2016.

[9] Porcu, F., Olivo, A., Maternini, G., \& Barabino, B., Evaluating bus accident risks in public transport. Transportation Research Procedia, 45, pp. 443-450, 2020.

[10] Barabino, B., Bonera, M., Maternini, G., Olivo, A., \& Porcu, F. (2021). Bus crash risk evaluation: An adjusted framework and its application in a real network. Accident Analysis and Prevention, 159, 106258. https://doi.org/10.1016/j.aap.2021.106258 
[11] Borghetti F., Frassoldati A., Derudi M., Lai I. \& Trinchini C., Safety in road tunnels: accident data analysis of the Italian motorway A24 and A25. Chemical Engineering Transactions, 82, pp. 307-312, 2020.

[12] Imprialou, M., \& Quddus, M., Accident data quality for road safety research: current state and future directions. Accident Analysis and Prevention, 130, pp. 84-90, 2019.

[13] Schlögl, M. \& Stütz, R., Methodological considerations with data uncertainty in road safety analysis. Accident Analysis and Prevention, 130, pp. 136-150, 2019.

[14] European Road Assessment Program, RAP Crash Risk Mapping: Technical Specification, 2020.

[15] Porcu, F., Olivo, A., Maternini, G., Coni, M., Bonera, M. \& Barabino, B., Assessing the risk of bus crashes in transit system. European Transport-Trasporti Europei, 81(4), 2021.

[16] ACI Automobile Club d'Italia, The road road accident map, Online: available at http:// www.aci.it/Archive-News/News.html? Tx_ttnews\%5Btt_news\% 5D=2391 \& cHash=a cea10e79cbd173913061eebf0a37b0e (accessed April 2021).

[17] Directorate General for Road Safety - Ministry of Infrastructure and Transport. Studies for the evaluation of the social costs of road accidents, 2017.

[18] Lane, R., Cleaning open graded asphalt to improve safety. Proceedings of the International Surface Friction Conference, Christchurch, New Zealand, 2005.

[19] Ahmed, F., 2015. Porous asphalt clogging performance under Swedish conditions, Master's thesis, Royal Institute of Technology, Civil and Architectural Engineering. 